\title{
The Impact of Green Supply Chain Management on Firm Performance: A Case of Manufacturing Industry of Karachi
}

\author{
Muhammad Saad ${ }^{1}$ \& Danish Ahmed Siddiqui ${ }^{1}$ \\ ${ }^{1}$ Karachi University Business School, University of Karachi, Pakistan \\ Correspondence: Muhammad Saad, Research Scholar, Karachi University Business School, University of Karachi, \\ Pakistan.
}

Received: March 28, 2019

Accepted: September 25, 2019

Online Published: November 25, 2019

doi:10.5430/jms.v10n5p48

URL: https://doi.org/10.5430/jms.v10n5p48

\begin{abstract}
This paper explored advancement in what performance factors affect Green Supply Chain Management practices of the firms. Data was collected through survey questionnaire, adopted and disseminated to 200 different employees working in different organizations based in Karachi that were associated with supply chain management activities. Data was analyzed using Structural Equation Modeling. Results showed that environmental and financial performance of organization has no statistically significant association with green supply chain management. Whereas, organizational performance produced a positive and significant impact. The results are significant for managers of manufacturing organizations in improving the practices of green supply chain management and achieve competitive position in the industry.
\end{abstract}

Keywords: green supply chain, firm financial performance, firm operational performance, green procurement, firm environment performance, recycle, remanufacturing, green logistics

\section{Introduction}

The Institute of Manufacturing Research at Michigan State University proposed the main idea of a green supply chain in 1996. The motivation behind this idea was to think about the effect on the environment and to consider the manufacturing of supply chain from the perspective of resource optimization. Improvement issues. In other words, from the earliest starting point of the crude material acquisition time of the item, following and control are completed, so the item is in consistence with ecological security guidelines amid the plan and advancement organize, in this manner diminishing the mischief caused to the earth amid the utilization time frame and the restitution time frame. Around then, the green store network just contained the two implications of ecological insurance and vitality protection, which is to deliver the most earth agreeable items with the least vitality and the greenest materials.

Several authors make other contributions to the definition of green supply chain from different points of view, for example, Srivastava (2007) talks about the unification of environmental practices throughout the processes (design, procurement, manufacturing, deliveries to the final client), and therefore the members of the chain, also considering a closure, which is the final disposal of the product that allows recognizing a green supply chain as a closed cycle process, where the product is theoretically returned at the end of its useful life to manufacturing processes where reprocess: some components are recycled, re-manufactured, re-used, and some are expected to be the least, they are wasted (Teixeira et al. 2016)(Govindan, Kaliyan \& Kannan).

GSCM is an advancement of SCM. As rivalry heightened during the 1990s, expanded familiarity with green practices has incited organizations to act morally and socially mindful in their supply chains. Toward the start of 1995, GSCM had pulled in extraordinary logical intrigue; GSCM then keeps on being a worry as of not long ago. With these practices, the organization creates ecological administration procedures because of changes out in the open and shopper consciousness of the earth and effects on store network activities.

According to Teixeira et al. (2016), green supply chain management emphasized on environmental protection of the organizational activities and promotes integrated environmental as well as environmental development of organization. According to Luthra, Garg, \& Haleem, (2016), main aspect of green supply chain management is to make minimal waste production and less pollution, say no to integration of harmful ingredients and minimal side effect of entire supply chain activities. 
Currently, different international firms have realized the significance of green supply chains. Many multinational organizations like Procter and Gamble, Ford, General Motors, Nike and Hewlett-Packard have explored and assess the implications of implementing green supply chain management models. According to Jabbour, \& de Sousa Jabbour, (2016), focusing on green supply chain management model results in achieving competitive position through maximizing firm operational performance.

According to Khan, Zhang, Golpîra, \& Dong, (2018), a high involvement of organization in GSCM is particularly considered as integrating improvements in the competitiveness of organization and making improvement in organizational image, innovative capabilities and overall profitability of firms. The competitive implications related to implementation of green supply chain management according to Subhani, Hasan, \& Osman, (2012) are significant for the organization. Effective implementation of green supply chain management has indicated that operational, financial and environmental performance of organization can be improved and organizations can gain competitive position along with improving overall efficiency. Manufacturing industry in Pakistan should pay attention to the practice of green supply chain management for achieving good results. Therefore, this research on supply chain management will focus on identifying and exploring the impact of green supply chain management on organizational performance and gaining competitive advantages in manufacturing industry in Karachi.

According to the research study conducted by Khan, Zhang, Golpîra, \& Dong, (2018) indicated that green distribution and green transportation has statistically significant association with organizational performance. This research study focuses on FMCG operating in Pakistan. However, this research study is limited to elaborate and clarify the construct of organizational performance. This results in developing opportunity for future studies to focus on identifying specific construct of organizational performance and execute research study that identify impact of GSCM on specific aspects of organizational performance instead of focusing on overall performance developing ambiguity for practical implications of the study.

A research study conducted by Subhani, Hasan, \& Osman, (2012) focus on the variable green supply chain management and indicated different factors that results in impeding the utilization and implementation of green supply chain management in small and medium enterprises operating in Pakistan. According to the findings of the study, it is indicated that governmental regulations and customer pressure are source of promoting GSCM in small and medium enterprises operating in Pakistan. The finding of this research study were limited to SMEs operating in Pakistan and also lacks the identification of implications of GSCM to impact on organizational performance.

Considering the gaps of the research studies, it is identified that limited target population and research sites are important aspect to be consider to execute a research. Previous research studies related to GSCM are limited to considering organizational performance as a holistic construct that results in developing ambiguity for managers to practically implementing the implications of GSCM. Moreover, previous research studies are conducted within specific geographical location as well as in specific industries. Therefore, considering different geographical locations and specific industry would result in advancing the existing knowledge base related to GSCM. Moreover, with context to Pakistan, the theoretical development within green supply chain management is limited to specific variables and lacks realistic implementation of GSCM. Therefore, this research will contribute the academic and managerial literature through considering operational, environmental and financial performance as diverse dependent variables elaborating the construct of organizational performance.

\section{Literature Review}

This section of the study explores basic foundations of GSCM and executes a comprehensive discussion with the integration of scholarly resources related to its impact of green supply chain management on performance of the organization.

According to Laari (2016) operational performance of organizations is affected by different characteristics of firm, however practices of GSCM results is impacting operational performance of organization. Moreover, according to Song, Cai, \& Feng (2017) indicated that the impact of different dimensions of GSCM on operational performance of a firm.

Mafini, \& Loury-Okoumba, (2018) green purchasing, reverse logistics, green manufacturing and environmental collaboration have strong associated with operational performance.

A research study conducted by Laari, (2016) aim to make contribution to explore and discuss implications of green supply chain management practices. This study discusses GSCM with perspective of drivers and performance implications associated with implementation of green supply chain management. In this research study, researcher emphasize on Finnish national logistics conducting a survey process for data collection from 2700 respondents. The 
findings of the research study indicated that there exist a positive association between firm performances and green supply chain management. The results indicated that operational performance of organizations is affected by different characteristics of firm, however practices of green supply chain management results in impacting operational performance of organization. This research study provides coherent information related to implication of GSCM, however this research is based on cross sectional survey data that results in application of results for a limited time period.

Song, Cai, \& Feng (2017) conducted a research study investigating the impact of different dimensions of GSCM on operational performance of a firm. This research study is conducted with the integration of configuration and contingency perspective. Cluster analysis and hierarchal regression model is used for analyzing and conducting statistical testing. This research study is conducted in the manufacturing sector operating in Shanxi, Shandong, Beijing, Guangdong and Jiangsu. The results of the research support that practices of GSCM have significant association with the operational performance of organization.

Another examination contemplates directed by Mafini, and Loury-Okoumba, (2018) investigate the execution of green inventory network the executives rehearses in the SME area working in South Africa. This exploration think about intends to survey the affiliation existing between operational execution and production network execution with green inventory network the executive's exercises, gathering information from 219 SMEs in Gauteng. As per the consequences of the examination, green buying, turn around coordination's, green assembling and natural cooperation have solid related with operational execution.

\subsection{Green Supply Chain Management and Firm Financial Performance}

An exploration think about directed by Marhamati, and Azizi, (2017) additionally investigate the effect of green production network the board on intensity and execution of firm. This examination consider is directed in Shiraz Industrial Estate through gathering information from 110 respondents have a place with various administrative and official layers. The outcomes demonstrated that green practices of association have critical affiliation execution of association and expanding firm aggressiveness. By and large aftereffects of the investigation recommended that sustaining the green store network the board rehearses have important effect on competiveness of association thus expanding the possibilities of improving money related execution and fortifying the incomes and benefits of association.

A research study conducted by Laari, (2016) aim to make contribution to explore and discuss implications of green supply chain management practices. This study discusses GSCM with perspective of drivers and performance implications associated with implementation of green supply chain management. In this research study, researcher emphasize on Finnish national logistics conducting a survey process for data collection from 2700 respondents. The discoveries of the exploration think about showed that there exists a positive relationship between firm exhibitions and green production network the board. It is indicated that GSCM have strong associated with financial performance with the mediating role of making improvement in environmental practices.

A research study conducted by Feng et al (2018) assessed the impact of an integrated GSCM on execution improvement of an organization. This research study is conducted in automotive manufacturing sector of China with the integration of 126 manufacturers conducted a survey process for data collection. It is identified in the results that GSCM is one of the important strategic choice that is identified with budgetary execution with the intervening job of operational and ecological execution improvement.

\subsection{Green Supply Chain Management and Firm Environmental Performance}

Muma, Nyaoga, Matwere, and Nyambega, (2014) explore the effect of green inventory network the executives on natural execution. This examination contemplate center around tea preparing organizations in Kericho County in Kenya. Distinctive 32 organizations partook in the information accumulation process and numerous relapse demonstrating was utilized to test the speculation. The outcomes showed that there exists solid connection between natural execution and GSCM.

Based on research by Khaksar, Abbasnejad, Esmaeili and Tamošaitienè (2016) intended to evaluate the connection between green providers, green advancement, natural execution and the upper hand of the bond business, an essential industry in Iran. The examination is clear in nature and depends on connection and auxiliary correlation demonstrating. The administrators and specialists of the Fars Province Cement Company were chosen as research tests. The consequences of information examination demonstrate that there is a positive and vital connection between green providers, green development and hierarchical ecological execution, while there is a negative yet imperative connection between green providers, green advancement and authoritative natural execution. There is additionally a 
noteworthy positive connection between's green development and ecological execution and natural execution and upper hand.

An exploration thinks about led by Feng et al (2018) evaluate the effect of a coordinated GSCM on execution improvement of an association. This exploration thinks about spotlight on connection among operational and natural execution with green store network the board and budgetary execution of the association. This exploration ponder is led in car fabricating area of China with the integration of 126 manufacturers conducted a survey process for data collection. It is identified in the results that GSCM is one of the important strategic option that is related to operational performance of organization as well as environmental performance. This research study is conducted in automotive manufacturing industry in China, in this way the consequences of the investigation would not be summed up to Pakistani manufacturing industry. Moreover, different cultural setting would result in attaining different results.

\section{Research Methodology}

The researchers identified sampling techniques, target groups/groups, sample sizes, statistical techniques, questionnaires and measurement tools.

Accommodation inspecting is a non-likelihood testing strategy in which subjects are chosen since they are open and available to specialists. Subjects were picked simply because they were the most straightforward to enlist in the investigation, and the specialists did not consider choosing subjects that speak to the whole populace. According to Bryman, \& Bell, 2015, using sample sampling techniques, sample bias may occur, but when choosing a convenient sampling, researcher will get the exact advantage. Research participants will conduct the investigation process by facilitating the selection of samples and by identifying a simple and convenient method.

Employees associated with supply chain management activities in selected organization are considered as main target audience of the study. About 200 respondents will be selected on convenience basis as a sample size through accessing different organization as per the convenience of the researcher.

\subsection{Instrument}

The data in this research will be collected through using questionnaire that used 5-point Likert Scale. Likert scaling in the poll include five distinct focuses including firmly dissent (1) to emphatically concur (5). The legitimacy of the survey was evaluated with the help of experts accessible related with the exploration work. The questionnaire was developed with the integration of different questionnaire adopted from past research studies (Song, Cai, \& Feng, 2017; Mafini, \& Loury-Okoumba, 2018).

In the wake of gathering the information, the gathered information will be investigated utilizing the sociology factual programming bundle programming. The software helps perform a variety of statistical tests that are applied to collect data. These statistical tests include reliability analysis, factor analysis, and regression analysis. Structural comparison modeling is often referred to as structural comparison modeling (SEM). The SEM-PLS method is integrated between factor analysis, structural model and path analysis.

\subsection{Demographic Analysis}

Respondents were approached to demonstrate their own statistic data in the poll. Demographic section of the questionnaire was divided into five different questions identifying gender, age, education, Job level and job tenure of the respondents. This particular information was obtained in order to assure that sample population of the research was diverse hence minimizing the risk of any kind of bias in the process of data collection.

Results of demographic analysis is identified that there were $93.0 \%$ male respondents and $7.0 \%$ female respondents. Moreover, it is also identified that respondents belong to different age groups. According to the results it is identified that $6.0 \%$ respondents belong to $20-30$ age group, $16.5 \%$ respondents belong to $31-40$ age group, $42.0 \%$ respondents belong to 41-50 age group and 34.0\% belong to 51-60 age group and 1.5\% respondents were above 60 years. Results also identify the education background of the respondents. According to the results, it is identified that out of 200 respondents, $33.5 \%$ respondents were diploma holder, $36.0 \%$ respondents were bachelor, $17.5 \%$ respondents were Masters, $8.5 \%$ were enrolled in $\mathrm{PhD}$ programs and $4.5 \%$ possess other educational qualifications. It is also identified that $33.0 \%$ of the total respondents were working as managerial level. $35.0 \%$ of the respondents were supervisors, $19.5 \%$ were workers and $7.0 \%$ respondents were working at different job roles in their respective organizations.

\section{Descriptive Analysis}

Respondents were asked with various inquiries that incorporates proclamations distinguishing the hugeness of GSCM rehearses for operational, monetary and ecological execution of the association. As indicated by the 
discoveries it is distinguished that dominant part of the respondents were concurring with the explanations that green store network the executives rehearses results in natural upgrades through cross practical participation, providers to utilize ecological bundling, joint choices with providers and natural effect on items. It is additionally recognized that larger part of respondents were concurred that participation with clients is imperative for eco-plan. In addition, respondents considered advancement of common comprehension of duties as an essential piece of green store network the executives rehearses. And furthermore, it is distinguished that working with clients to lessen ecological issues, water squander decrease and strong waste decrease critical perspective for improving execution of association through green store network the board rehearses.

\subsection{Inferential Statistics}

Different statistical inferences and tests were executed in order to attain logical results from the collected data. These statistical tests include validity and reliability analysis, regression analysis through structural equation modeling. These statistical tests were executed through utilizing SPSS and Smart PLS 3.0.

\subsection{Model Measurement}

Two unique models are incorporated into the PLS show that are estimation display and auxiliary model. In this segment estimation display examination is executed that includes speaking to the external relationship between various builds of the exploration consider, Moreover, auxiliary model includes portrayal of inward connections between the develop of the investigation. For unwavering quality estimations, Cronbach's alpha, composite dependability and mean change extraction (AVE) are utilized.

To distinguishing the unwavering quality of develop, Cronbach's alpha is utilized. As per the standard guideline, least estimation of 0.7 is considered as satisfactory unwavering quality of the builds. Moreover, composite unwavering quality is executed as another measure for inside consistency of the develops utilized in the exploration think about. For this specific inward consistency test, the incentive between 0.7 to 0.9 is acknowledged.

Convergent validity emphasizes the inclusion of external loads and assesses whether the indicators are positively correlated with other indicators of the same structure. AVE is used to measure the effectiveness of convergence to a certain level. A value of AVE greater than 0.5 means that the composition is interpreted as $50 \%$ or more depending on the change of the indicator. The indicator and external charge must be above 0.708 , but if the removal has no effect on the reliability of the composite, the indicator must remain between 0.4 and 0.7 and remain the same.

Discriminant validity is used to measure the degree of difference between structure and other structures and to represent unique and distinct phenomena. There are two ways to measure the effectiveness of discrimination. First, the external load based on the indicator must be higher than the load of all other structures. The second method, Fornell-Larcker, depends on the square root of AVE, which is higher than other combinations.

\subsection{Convergent Validity}

So as to survey legitimacy, as indicated by Henseler et al. (2009), two distinct kinds of legitimacy are assessed including the discriminant legitimacy and focalized legitimacy. Through concurrent legitimacy, scientists recognize set of markers speaking to the comparative basic build. Also, for surveying the concurrent legitimacy, Average Variance Extracted utilize utilized. As indicated by Fornell and Larcker (1981) in any event 0.5 estimations of AVE propose satisfactory focalized legitimacy. The qualities for Average Variance Extracted (AVE) can be found in Table 4.2. The qualities more noteworthy than 0.5 demonstrate that everything have sufficient merged legitimacy, Moreover, so as to give focalized legitimacy, it is distinguished that composite unwavering quality ought to be more than 0.7 and AVE ought to be progressively 0.5 .

This table indicate that outer loading values of all items included in the model are more prominent than 0.5. Moreover, the composite dependability of every single incorporated thing are more noteworthy than 0.7, AVE values are greater 0.5 and esteem for CronBach Alpha is also noteworthy than 0.7. These results explicitly indicated that contracts included in the model are reliable and valid to be used in the research work.

\begin{tabular}{lllll}
\hline & $\begin{array}{l}\text { Cronbach's } \\
\text { Alpha }\end{array}$ & rho_A & $\begin{array}{l}\text { Composite } \\
\text { Reliability }\end{array}$ & $\begin{array}{l}\text { Average Variance } \\
\text { Extracted (AVE) }\end{array}$ \\
\hline Environmental performance & 0.734 & 0.743 & 0.848 & 0.650 \\
\hline Financial performance & 0.720 & 0.939 & 0.867 & 0.766 \\
\hline
\end{tabular}




\begin{tabular}{lllll}
\hline Green supply chain management & 0.905 & 0.908 & 0.927 & 0.681 \\
\hline Operational performance & 0.905 & 0.908 & 0.927 & 0.681 \\
\hline
\end{tabular}

\subsection{Discriminant Validity}

According to Matthews, (2017), discriminant validity refers to the level of the construct differs from each other. It is a measure of identifying the extent of difference exist between each overlapping construct included in the model. Matthews, (2017) identified that researchers can evaluate Discriminant validity through using three different methods including cross loading of indicators, Heterotrait-monotrait (HTMT) ratio of correlation and Fornell \& Larcker criterion.

\begin{tabular}{lllll}
\hline Fornell-Larcker Criterion & & & & \\
\hline & $\begin{array}{l}\text { Environmental } \\
\text { performance }\end{array}$ & $\begin{array}{l}\text { Financial } \\
\text { performance }\end{array}$ & $\begin{array}{l}\text { Green supply chain } \\
\text { management }\end{array}$ & $\begin{array}{l}\text { Operational } \\
\text { performance }\end{array}$ \\
\hline Environmental performance & 0.806 & & & \\
\hline Financial performance & -0.066 & 0.875 & & \\
\hline Green supply chain management & -0.096 & 0.149 & 0.825 & 0.825 \\
\hline Operational performance & -0.096 & 0.149 & 1.000 & \\
\hline
\end{tabular}

The main foundation that is included for surveying discriminant legitimacy is Fornell-Lacker standard. Through this methodology, look into contrasts the connection of dormant builds and the square base of the normal change extricated. For accomplishing the criteria of discriminant legitimacy, it is essential that square foundation of AVE of each build ought to be more prominent as contrast with the connection with different develops. As indicated by the outcomes, table 4.3 affirm the discriminant legitimacy of each develop in an ideal way. Another method for discriminant validity is identify cross loading of each item integrated in the model. Following is cross loadings of each item.

\subsection{Outer Loadings}

By observing the cross load, the factor load indicator for the specified construction must be higher than all other configurations, provided that the factor load cutoff is above 0.70. Except some of the individual items, all other items values are greater than 0.70 , hence confirming the discriminant validity.

\begin{tabular}{lllll}
\hline & $\begin{array}{l}\text { Environmental } \\
\text { performance }\end{array}$ & $\begin{array}{l}\text { Financial } \\
\text { performance }\end{array}$ & $\begin{array}{l}\text { Green supply chain } \\
\text { management }\end{array}$ & $\begin{array}{l}\text { Organizational } \\
\text { performance }\end{array}$ \\
\hline EP1 & 0.795 & & \\
\hline EP2 & 0.828 & & \\
\hline EP4 & 0.795 & & & \\
\hline FP1 & 0.795 & & \\
\hline FP2 & 0.949 & 0.853 & \\
\hline GSCM1 & & 0.851 & \\
\hline GSCM2 & & 0.874 & \\
\hline GSCM3 & & 0.845 & \\
\hline GSCM4 & & 0.769 & \\
\hline GSCM5 & & 0.751 & \\
\hline GSCM6 & &
\end{tabular}




\begin{tabular}{ll}
\hline OP1 & 0.853 \\
\hline OP2 & 0.851 \\
\hline OP3 & 0.875 \\
\hline OP4 & 0.845 \\
\hline OP5 & 0.769 \\
\hline OP6 & 0.751 \\
\hline
\end{tabular}

Another proportion of discriminant legitimacy is the Heterotrait-monotrait (HTMT) relationship proportion. Henseler et al. used Monte Carlo proliferation concentrates to find the unrivaled execution of the system and found that HTMT can achieve higher affectability and expresses levels (97\% to 99\%) and Fornell-Lacker (20.82\%) contrasted with cross-stacking benchmarks $(0.00 \%)$. A HTMT esteem near 1 determines a nonappearance of discriminant legitimacy.

\begin{tabular}{lllll}
\hline Heterotrait-Monotrait Ratio (HTMT) & & & \\
\hline & $\begin{array}{l}\text { Environmental } \\
\text { performance }\end{array}$ & $\begin{array}{l}\text { Financial } \\
\text { performance }\end{array}$ & $\begin{array}{l}\text { Green supply chain } \\
\text { management }\end{array}$ & $\begin{array}{l}\text { Organizationa } \\
\text { 1 performance }\end{array}$ \\
\hline Environmental performance & & & & \\
\hline Financial performance & 0.131 & & & \\
\hline Green supply chain management & 0.118 & 0.171 & & \\
\hline Operational performance & 0.118 & 0.171 & 1.104 & \\
\hline
\end{tabular}

\subsection{Show Fit Measures}

The wellness of the model in SEM-PLS is characterized by different estimates, for example, institutionalized root-mean-square lingering (SRMR), and the careful model fits like d_ULS and d_G, Normed Fit Index (NFI), and $\chi^{2}$ (Chi-square). It comprising the deliberate estimation of both immersed display just as the assessed model as detailed in above Table. The soaked model evaluates the connection between's everything develops. The assessed model, then again, considers display structure and its dependent on all out impact conspire. Presently, we will portray each model fit measure in subtleties to comprehend its suggestions.

\subsection{Standardized Root-Mean-Square Remaining}

The SRMR measure depends on changing both the covariance grids, test and anticipated covariance framework into the relationship lattices and afterward processing the distinction between the model's inferred connection network and the watched relationship. The SRMR esteem ought to be under 0.10 for thinking about any model to have a solid match (Hu and Bentler 1998). The proposed model yields the SRMR esteem as 0.06, which is moderately lesser than 0.10 . Thus, the proposed model is a solid match.

\begin{tabular}{lll}
\hline Fit Summary & & \\
\hline & Saturated Model & Estimated Model \\
\hline SRMR & 0.091 & 0.091 \\
\hline d_ULS & 1.270 & 1.270 \\
\hline d_G & 0.435 & 0.435 \\
\hline Chi-Square & 631.868 & 631.868 \\
\hline NFI & 0.722 & 0.722 \\
\hline
\end{tabular}




\subsection{Careful Model Fit Tests}

The careful model fit test is registered by the contrast between the relationship lattice suggested by the proposed model and the exact connection network (Dijkstra and Henseler 2015). Two of the most broadly utilized accurate model fit tests are d_LS and d_G. Both of the model fit tests contrast just in the manner by which distinction between networks is registered. D_LS figures the distinction by utilizing squared Euclidean separation, though geodesic separation is processed in the d_G fit test. The estimations of d_LS and d_G ought to be non-critical $(p>.05)$ for the solid match demonstrate. The proposed model yields the estimation of d_LS and d_G as 0.439 and 0.283 individually, which demonstrates that the proposed model is a solid match.

\section{$\chi^{2}$ (chi-square) and degrees of opportunity}

$\chi^{2}$ is one of the measures for evaluating model fit. $\chi^{2}$ can be figured as $\mathrm{x} 2=(\mathrm{N}-1) * \mathrm{~L}$, where $\mathrm{N}$ is the quantity of perceptions, and L is most extreme probability work (Lohmoller 1989). Thus, Degree of opportunity (df) can be figured as $\mathrm{df}=(\mathrm{K} 2+\mathrm{K}) / 2-\mathrm{t}$, where $\mathrm{K}$ is the show factors in the PLS way model and $\mathrm{t}$ is the quantity of free factors to appraise the model suggested covariance network. The proposed model yields the estimation of $\chi^{2}$ as 631.86 , which suggests that the proposed model is a solid match.

\subsection{Normed Fit Index}

NFI is one of the most punctual estimates utilized in SEM writing (Bentler and Bonett 1980). NFI registers the estimation of $\chi^{2}$ (Chi-square) and afterward contrast it and the benchmark show.

$$
\text { NFI }=1-\text { chi-sq (Proposed Model)/chi-sq (Null Model). }
$$

NFI yields the incentive somewhere in the range of 0 and 1 . The model is viewed as a solid match for the qualities more prominent than 0.75 . The proposed model in the examination yields the estimation of NFI as 0.72 , which is route over the limit and consequently the model is viewed as a solid match.

\subsection{Bootstrapping Results}

Bootstrapping is one of the key strides in PLS-SEM, which gives the data of strength of coefficient gauge. In this procedure, countless examples are drawn from the first example with substitution (Hair et al. 2016). We have done the bootstrapping for 2000 runs, so as to have progressively vigorous outcomes which can be generalizable. Subsequent to running the bootstrap schedule, SmartPLS demonstrates the t-values for basic model assessments got from the bootstrapping strategy. The consequences of way coefficients for all the theory are appeared in the accompanying table. The t-esteem more noteworthy than $1.96(\mathrm{p}<.005)$ demonstrates that the relationship is critical at $95 \%$ certainty level $(\alpha=0.05)$.

\subsection{Path Diagram}

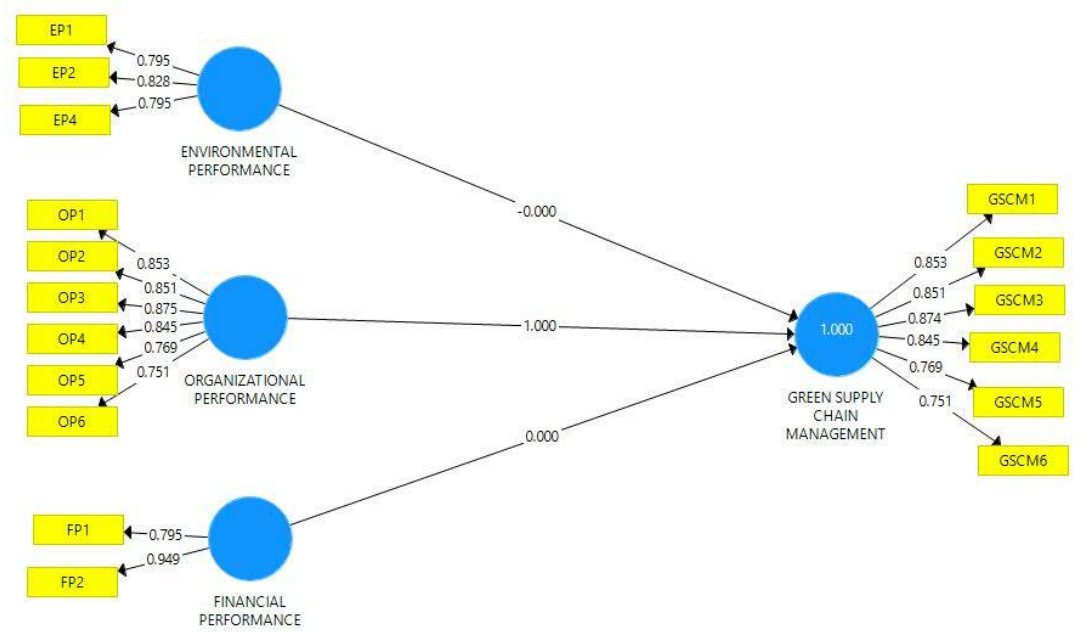

The hypothesis testing and structural method testing is executed through Partial Least Square calculating the path coefficients. Research model included in this research study proposes 9 hypotheses. Executing the PLS algorithm 
and Bootstrapping calculations in Smart PLS software results in obtaining the path coefficient of variable relations that indicate that strength of the associations and P-value for identifying statistical significance of the relationship.

\subsection{Structural Modeling}

According to the results, it is identified that there exist statistically significant association between organizational performance and green supply chain management with $\mathrm{p}$ value is equal to 0.000 .

\begin{tabular}{llllll}
\hline & $\begin{array}{l}\text { Original } \\
\text { Sample (O) }\end{array}$ & $\begin{array}{l}\text { Sample } \\
\text { Mean (M) }\end{array}$ & $\begin{array}{l}\text { Standard } \\
\text { Deviation } \\
(\text { STDEV })\end{array}$ & $\begin{array}{l}\text { T Statistics } \\
(\mid \mathrm{O} / \text { STDEV } \mid)\end{array}$ & P Values \\
\hline $\begin{array}{l}\text { Environmental performance -> green } \\
\text { supply chain management }\end{array}$ & 0.000 & 0.000 & 0.000 & 0.241 & 0.810 \\
\hline $\begin{array}{l}\text { Financial performance -> green supply } \\
\text { chain management }\end{array}$ & 0.000 & 0.000 & 0.000 & 0.344 & 0.731 \\
\hline $\begin{array}{l}\text { Operational performance -> green } \\
\text { supply chain management }\end{array}$ & 1.000 & 1.000 & 0.000 & $6,583.621$ & 0.000 \\
\hline
\end{tabular}

Above is the table which displays the results of hypothesis, the variable of Organizational performance having relationship is positive as the $\mathrm{p}$ values is less than 0.05 which confirms that it has a positive impact on Green supply chain management. The $\mathrm{T}$ value shows there is a significant difference among the variables and the $\mathrm{P}$ values depicts the decision no relation has been rejected and the alternative hypothesis have been supported on the basis of $\mathrm{p}$ values.

According to the results it is identified that environmental performance of organization has no statistically significant association with green supply chain management ( $\mathrm{P}$-value $=0.810$ ). Moreover, it is identified that financial performance of organization has no statistically significant association with green supply chain management (P-value $=0.731)$.

\section{Discussion}

The predefined aim of this research study is to present the assessment of three different constructs and the impact of green supply chain management on these three constructs. This research study focus on firm performance, organizational performance and environmental performance with three specific research hypothesis.

Hypothesis 1 claims that there is statistically significant impact of green supply chain management on environmental performance of the organization. However, this hypothesis was not accepted due to obtaining inadequate evidences to reject the null hypothesis.

Hypothesis 2 claims that there is statistically significant impact of green supply chain management on financial performance. However, this hypothesis was not accepted due to inadequate evidences to reject the null hypothesis.

Hypothesis 3 claims that there is statistically significant impact of green supply chain management on organizational performance. This hypothesis was accepted due to adequate evidences to reject the null hypothesis.

Following table summarizes the testing of hypothesis:

\begin{tabular}{llll}
\hline Hypothesis & Statistical Significance & Accepted or Rejected \\
\hline $\begin{array}{l}\text { Alternative hypothesis: H1: There is statistically } \\
\text { significant impact of galue }=0.810\end{array}$ & Rejected \\
environmental performance of the organization & \\
\hline $\begin{array}{l}\text { Alternative hypothesis: H2: There is statistically } \\
\text { significant impact of green supply chain management on } \\
\text { financial performance. }\end{array}$ & Rejected \\
\hline $\begin{array}{l}\text { Alternative hypothesis: H3: There is statistically } \\
\text { significant impact of green supply chain management on } \\
\text { organizational performance. }\end{array}$ & & \\
\hline
\end{tabular}


According to the results, it is identified that there exist statistically significant association between operational performance and green supply chain management with $\mathrm{p}$ value is equal to 0.000 . The variable of operational performance having relationship is positive as the $\mathrm{p}$ values is less than 0.05 which confirms that it has a positive impact on Green supply chain management. The $\mathrm{T}$ value shows there is a significant difference among the variables and the $\mathrm{P}$ values depicts the decision no relation has been rejected and the alternative hypothesis have been supported on the basis of $\mathrm{p}$ values. The results of the research indicated that there exist statistically significant associated between green supply chain management and operational performance. This result supports the findings of Laari, (2016), Feng et al (2018), Song, Cai, \& Feng (2017) and Mafini, \& Loury-Okoumba, (2018). Through this result, it is put forward that organizations should consider GSCM as one of the significant strategic option for making improvement in operational performance and gaining competitive position in the industry.

According to the results it is identified that environmental performance of organization has no statistically significant association with green supply chain management ( $\mathrm{P}$-value $=0.810$ ). Moreover, it is identified that financial performance of organization has no statistically significant association with green supply chain management (P-value $=0.731$ ). These results contradict the findings of many previous research. According to the findings of Zhang, Tse, Dai, \& Chan. (2017), Marhamati, \& Azizi, (2017) and Laari, (2016). However, the findings of the research study conducted by Marhamati, \& Azizi, (2017) supports the findings of this research that indicate that effective practices of GSCM is source of gaining competitive positon and increasing competitiveness of organization.

The findings of the research contribute to the development and advancing the existing knowledge base related to practices of GSCM and signifying the importance of green and sustainable practices. The findings of the research are important for manufacturing firms operating in Karachi in order to develop understanding with the significance of these practices and align their operations so that make effective contribution towards the clean and healthy environment for citizens of Karachi. Hence this research study is also significant for the contribution towards corporate social responsibility and enabling the organizations to play effective role.

\section{Conclusion}

Based on the survey results, there is a statistically significant relationship between operational performance and green supply chain management, with a p-value equal to 0.000 . Since the p-value is less than 0.05 , the operational performance variable is positive, confirming that this has a positive impact on the management of the green supply chain. This result supports the discovery of Laari, (2016), Feng et al. (2018), Song, Cai and Feng (2017), and Mafini and Loury-Okoumba (2018). This result suggests that organizations should view GSCM as one of the key strategic options for improving operational performance and achieving competitive position in the field. Based on the results, there is no statistically significant correlation between the organization's environmental performance and financial performance and green supply chain management. The results of Marhamati and Azizi (2017) support the results of this study, demonstrating that GSCM's effective practices are a source of competitive position and organizational competitiveness.

An exploratory research was executed with taking inductive and survey based approach as main research method. Diverse data was collected through primary as well as secondary sources. A survey questionnaire was adopted that was disseminated to 200 different employees working in different organizations based in Karachi and associated with supply chain management activities. SPSS was used to analyze the collected data and identifying meaningful information from the data collected.

According to the results, it is identified that environmental performance of organization has no statistically significant association with green supply chain management $(\mathrm{P}$-value $=0.810)$. Moreover, it is identified that financial performance of organization has no statistically significant association with green supply chain management (P-value $=0.731)$. The results indicated that organizational performance of organization has statistically significant association with green supply chain management (P-value $=0.000)$.

According to the results it is recommended that senior management in the organizations should focus on supporting the green supply chain management initiatives and its effective implementation. Moreover, it is important to develop a comprehensive structure to implement and monitor the green supply chain management implications.

Considering conducting future research with the integration of other industrial sector in Pakistan may lead towards advancing the existing knowledge base and developing understanding with the performance of organizations that is influenced by green supply chain management practices. This research study can be expanding into transportation and construction sector of Pakistan. Moreover, it is also important to explore and identify the awareness level of small and medium businesses regards to green supply chain management in the operations. Further research may also 
expand the advancement of knowledge base with the integration of case study analysis of any multinational organizations and identifying the successful implications of green supply chain management.

\section{References}

Bentler, P. M., \& Bonett, D. G. (1980). Significance tests and goodness of fit in the analysis of covariance structures. Psychological Bulletin, 88(3), 588. https://doi.org/10.1037/0033-2909.88.3.588

Chin, T. A., Tat, H. H., \& Sulaiman, Z. (2015). Green supply chain management, environmental collaboration and sustainability performance. Procedia CIRP, 26, 695-699. https://doi.org/10.1016/j.procir.2014.07.035

Diabat, A., Kannan, D., \& Mathiyazhagan, K. (2014). Analysis of enablers for implementation of sustainable supply chain management-A textile case. Journal of Cleaner Production, 83, 391-403. https://doi.org/10.1016/j.jclepro.2014.06.081

Dijkstra, T. K., \& Henseler, J. (2015). Consistent and asymptotically normal PLS estimators for linear structural equations. Computational Statistics \& Data Analysis, 81, 10-23. https://doi.org/10.1016/j.csda.2014.07.008

Dubey, R., Gunasekaran, A., \& Ali, S. S. (2015). Exploring the relationship between leadership, operational practices, institutional pressures and environmental performance: A framework for green supply chain. International Journal of Production Economics, 160, 120-132. https://doi.org/10.1016/j.ijpe.2014.10.001

Fahimnia, B., Sarkis, J., \& Davarzani, H. (2015). Green supply chain management: A review and bibliometric analysis. International Journal of Production Economics, 162, 101-114. https://doi.org/10.1016/j.ijpe.2015.01.003

Govindan, K., Kaliyan, M., Kannan, D., \& Haq, A. N. (2014). Barriers analysis for green supply chain management implementation in Indian industries using analytic hierarchy process. International Journal of Production Economics, 147, 555-568. https://doi.org/10.1016/j.ijpe.2013.08.018

Govindan, K., Muduli, K., Devika, K., \& Barve, A. (2016). Investigation of the influential strength of factors on adoption of green supply chain management practices: An Indian mining scenario. Resources, Conservation and Recycling, 107, 185-194. https://doi.org/10.1016/j.resconrec.2015.05.022

Green, K. W. Jr., Zelbst, P. J., Meacham, J., \& Bhadauria, V. S. (2012). Green supply chain management practices: impact on performance. Supply Chain Management: An International Journal, 17(3), 290-305. https://doi.org/10.1108/13598541211227126

Hair, J. F. Jr., Hult, G. T. M., Ringle, C., \& Sarstedt, M. (2016). A primer on partial least squares structural equation modeling (PLS-SEM). Sage Publications. https://doi.org/10.15358/9783800653614

Hu, L. T., \& Bentler, P. M. (1998). Fit indices in covariance structure modeling: Sensitivity to underparameterized model misspecification. Psychological Methods, 3(4), 424. https://doi.org/10.1037/1082-989X.3.4.424

Jabbour, C. J. C., \& de Sousa Jabbour, A. B. L. (2016). Green human resource management and green supply chain management: Linking two emerging agendas. Journal of Cleaner Production, 112, 1824-1833. https://doi.org/10.1016/j.jclepro.2015.01.052

Khaksar, E., Abbasnejad, T., Esmaeili, A., \& Tamošaitienè, J. (2016). The effect of green supply chain management practices on environmental performance and competitive advantage: a case study of the cement industry. Technological and Economic Development of Economy, 22(2), 293-308. https://doi.org/10.3846/20294913.2015.1065521

Khan, S. A. R., \& Qianli, D. (2017). Impact of green supply chain management practices on firms' performance: an empirical study from the perspective of Pakistan. Environmental Science and Pollution Research, 24(20), 16829-16844. https://doi.org/10.1007/s11356-017-9172-5

Khan, S. A. R., Zhang, Y., Golpîra, H., \& Dong, Q. (2018). The Impact of Green Supply Chain Practices in Business Performance: Evidence from Pakistani FMCG Firms. Journal of Advanced Manufacturing Systems, 17(02), 267-275. https://doi.org/10.1142/S0219686718500166

Kroonenberg, P. M. (1990). Latent variable path modeling with partial least squares. Journal of the American Statistical Association, 85(411), 909-911. https://doi.org/10.2307/2290049

Laari, S. (2016). Green supply chain management practices and firm performance: evidence from Finland.

Luthra, S., Garg, D., \& Haleem, A. (2016). The impacts of critical success factors for implementing green supply chain management towards sustainability: an empirical investigation of Indian automobile industry. Journal of 
Cleaner Production, 121, 142-158. https://doi.org/10.1016/j.jclepro.2016.01.095

Mafini, C., \& Loury-Okoumba, W. V. (2018). Extending green supply chain management activities to manufacturing small and medium enterprises in a developing economy. South African Journal of Economic and Management Sciences, 21(1), 12. https://doi.org/10.4102/sajems.v21i1.1996

Marhamati, A., \& Azizi, I. (2017). The Impact of Green Supply Chain Management on Firm Competitiveness. International Journal of Supply Chain Management, 6(4), 215-223.

Muma, B. O., Nyaoga, R. B., Matwere, R. B., \& Nyambega, E. (2014). Green supply chain management and environmental performance among tea processing firms in Kericho County-Kenya. International Journal of Economics, Finance and Management Sciences, 2(5), 270-276. https://doi.org/10.11648/j.ijefm.20140205.11

Scur, G., \& Barbosa, M. E. (2017). Green supply chain management practices: Multiple case studies in the Brazilian home appliance industry. Journal of Cleaner Production, 141, 1293-1302. https://doi.org/10.1016/j.jclepro.2016.09.158 